\title{
A Structure Design of Novel Photobase Generator and Application of a Photobase Generator to Negative Photosensitive Polyimides
}

\author{
Yuji Katayama ${ }^{\ddagger}$, Toshiaki Nagasawa and Hideaki Takahashi \\ Asahi-Kasei corporation Central R\&D Laboratories \\ 2-1 Samejima Fuji-city Shizuoka, Japan \\ katayama.yk@om.asahi-kasei.co.jp
}

\section{polyamic acid}

Key words: photobase generator photolithography photosensitive polyimide

\section{Introduction}

Polyimides (PIs) are used as engineering plastics because of their excellent mechanical properties. PIs are applied for photosensitive materials, i.e. photosensitive polyimides (PSPIs). Most of PSPIs are negative-type photosensitive materials with cross linked system which needs high temperature cure process to remove crosslink sites.

However those systems are difficult to apply for photosensitive cover lay in regards of flexible printed circuit (FPC) that is damaged against high temperature cure process.

PIs are synthesized from polyamic acids (PAAs) precursors under base catalyst condition. Therefore we have adopted photo base generators (PBGs) as a catalyst of PAA. We have developed the PBGs for alkaline developable negative-type PSPI (Scheme 1, Fig 1).

\section{Experimental}

\section{2-1. Synthesis of Photo Base Generators}

$1 \mathrm{Ph}-\mathrm{BA}$ was prepared as described in the literature.[1][2] $\quad \mathrm{C} 8$ was prepared by the following patent.[3] $\mathrm{C} 7 \mathrm{M}, \mathrm{C} 8 \mathrm{M}, \mathrm{C} 7 \mathrm{MPh}$, $\mathrm{C} 8 \mathrm{MPh}, \mathrm{TX}-8$ were prepared as described in Scheme 2 6. The abbreviations in Scheme 2 6 are as follows: MeMgI (Methyl magnesium iodide), PTSA ( $\mathrm{p}$ - toluene sulfonic acid), NaIO4 (Sodium periodate), $\mathrm{RuCl}_{3}$ (Ruthenium(III) chloride), $\mathrm{NH}_{2} \mathrm{OH} \cdot \mathrm{HCl}$ (Hydroxylamine hydrochloride), TCBC (Tricholorobenzoylchloride), DMAP (Dimethylaminopyrine), $\mathrm{NEt}_{3}$ (Triethylamine),
$\mathrm{POCl}_{3}$ (Phosphorus chloride oxide), $\mathrm{PhMgBr}$ (Phenylmagnesiumbromde), $\mathrm{Pd} 2(\mathrm{dba})_{3} \quad$ (Tris (dibenzylideneacetone)dipalladium $(0), \quad \mathrm{P}(\mathrm{tBu})_{3}$ $\mathrm{HBF}_{4}$ (Tri-t-butylphosphinetetrafluoroborate), $\mathrm{Cy}_{2} \mathrm{NM}_{2}$ (Dicyclohexylmethylamine).

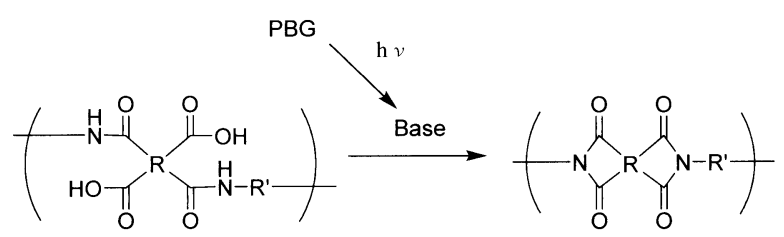

Scheme 1 PBG as a catalyst of PAA and alkaline developable negative-type PSPI
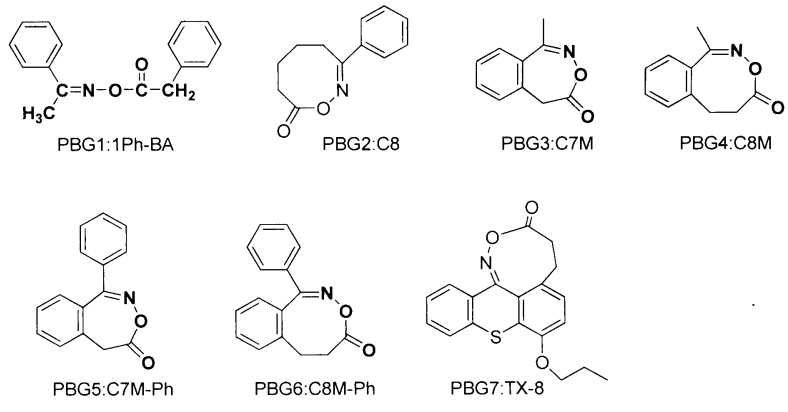

Fig.1 PBG samples

\section{2-2. Steady state spectroscopy}

UV spectra of PBGs were measured as polymethacrylonitrile (PMAN) films prepared by the following procedure. PMAN films (4 $\mu \mathrm{m}$ thickness) were prepared by spin-casting of methylethylketone (MEK) (500mg) solution containing PMAN (100 mg), PBG (10 mg) and 2,4-Diethyl-9H-thioxanthen-9-one (DETX) (3 $\mathrm{mg}$ ) on the $\mathrm{CaF}_{2}$ plate followed by baking at $70^{\circ} \mathrm{C}$ for $5 \mathrm{~min}$. 


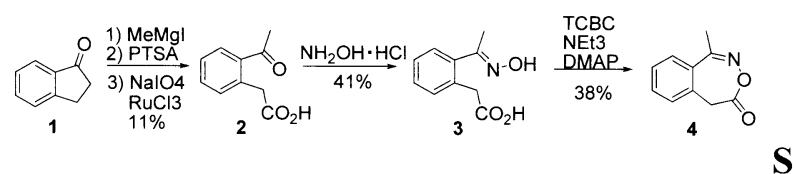

Scheme 2 Synthesis of PBG3:C7M

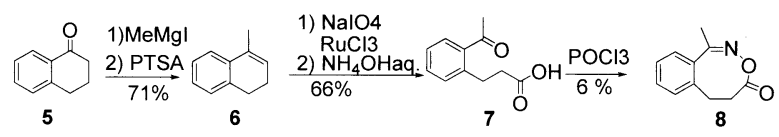

Scheme 3 Synthesis of PBG4:C8M

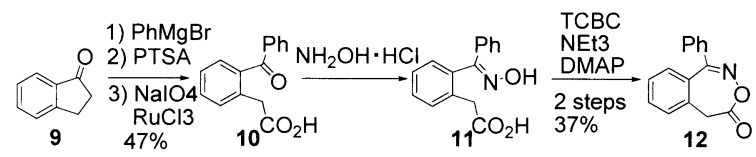

Scheme 4 Synthesis of PBG5:C7MPh

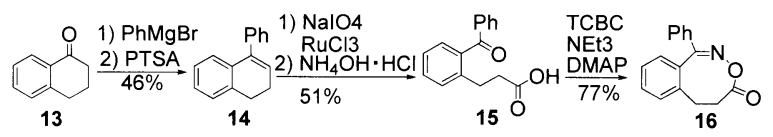

Scheme 5 Synthesis of PBG6:C8MPh

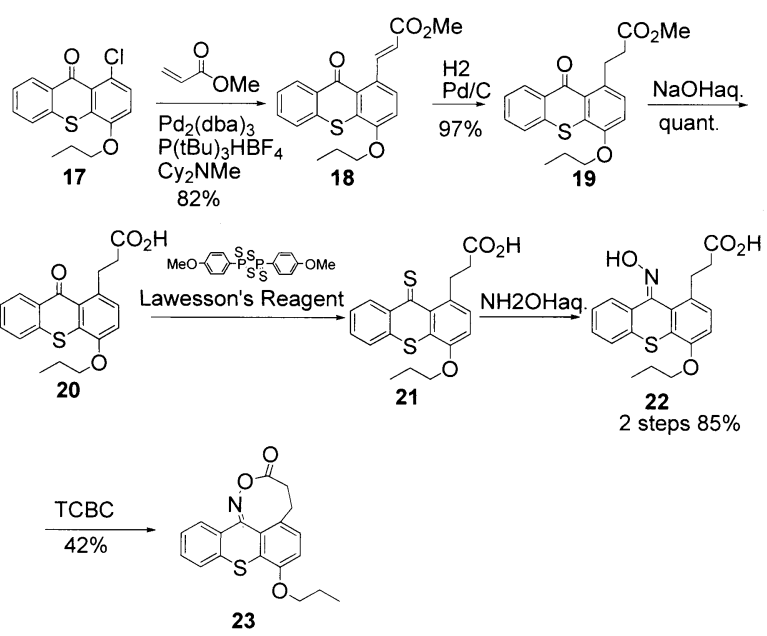

Scheme 6 Synthesis of PBG7:TX-8

\section{2-3. Photolysis experiment}

The photolysis of PBGs in PMAN films was conducted. High mercury lamp was used for the irradiation. The wave-length below $325 \mathrm{~nm}$ was cut by the filter. PMAN films ( $4 \mu \mathrm{m}$ thickness) were prepared by spin-casting of MEK $(500 \mathrm{mg}$ ) solutionon containing PMAN (100mg), PBG (10 $\mathrm{mg}$ ) and DETX (3 mg) on the $\mathrm{CaF}_{2}$ plate followed by baking at $70^{\circ} \mathrm{C}$ for $5 \mathrm{~min}$. The absorption intensities were measured by FT-IR spectra at 1760 $\mathrm{cm}^{-1}\left(\mathrm{~A}_{1760}\right)$ correspond to oxime. The photolysis rate was determined by the following equation.

\section{Photolysis Rate $=$ \\ $\left(\mathrm{A}_{1760} \quad\right.$ (samp) $-\mathrm{A}_{1760} \quad$ (init) $) /\left(\mathrm{A}_{1760} \quad\right.$ (fin) $-\mathrm{A}_{1760}$ (init) $) \times 100$ \\ Subscripts between parentheses} following $\mathrm{A}$ in the equation indicates the state of the polymer films; e.g. (samp) is the polymer sample at each exposure dose ; (init) is unexposed film; (fin) is completely photolysis film.

\section{2-4. Thermal stability experiment}

The thermal stability experiment was carried out by TG/DTA under air condition.

\section{2-5. Synthesis of poly(amic acid) PAA-1}

Poly(amic acid)-1 (PAA-1) was synthesized as follows. 4,4'- Oxydiphthalic anhydride (ODPA) (10.3 g, $33.2 \mathrm{mmol}$ ) solution in $\gamma$-butyrolactone $(\gamma \mathrm{BL})(60.0 \mathrm{ml})$ was added to 1,3-bis(4-aminophenoxy)benzene (TPE-R) (9.41 g, $9.41 \mathrm{mmol})$ with stirring. The mixture was stirred at room temperature for 12 hour to give a viscous solution. The yield was quantitative. Number-average molecular weights (Mn) and weight-average molecular weights (Mw) were 30,000 and 63,000, respectively, determined by gel permeation chromatography (GPC).

\section{2-6. Synthesis of poly(amic acid) PAA-2}

Poly(amic acid)-2 (PAA-2) was synthesized as follows. To a ODPA $(6.2 \mathrm{~g}$, $20.0 \mathrm{mmol}$ ) solutiuon in $\mathrm{N}$-methylpyrrolidone (NMP) (47.24 $\mathrm{ml})$ was added 1,3-bis(3-aminophenoxy)benzene (APB) (5.61 g,19.2 mmol) with stirring. The mixture was stirred at room temperature for 12 hour to give a viscous solution. The yield was quantitative. $\mathrm{Mn}$ and $\mathrm{Mw}$ were 20,000 and 70,000 , respectively, determined by GPC.

\section{2-7. Imidization degree}

To a polymer solution of PAA-1 (2.5 g) were added PBG (50 mg), DETX (14 mg) and $\gamma \mathrm{BL}(0.5 \mathrm{~g})$. These solutions were spin-casted on a silicon wafer, and baked at $95{ }^{\circ} \mathrm{C}$ for $15 \mathrm{~min}$. The films were exposed at $2,000 \mathrm{~mJ} / \mathrm{cm}^{2}$ by using high pressure mercury lamp. We have achieved the post-exposure-baking at $140{ }^{\circ} \mathrm{C}$ for $30 \mathrm{~min}$ 
and at $330{ }^{\circ} \mathrm{C}$ for $30 \mathrm{~min}$ sequentially. Absorption intensities of FT-IR spectrum at $1380 \mathrm{~cm}^{-1}\left(\mathrm{~A}_{1380}\right)$ assigned as imide were measured. The imidization degree was determined using the following equation.

$$
\text { Imidization degree }=
$$

$\left(\mathrm{A}_{1380 \text { (samp) }}-\mathrm{A}_{1380 \text { (init) }}\right) /\left(\mathrm{A}_{1380 \text { (fin) }}-\mathrm{A}_{1380 \text { (init) }}\right) \times 100$

Subscripts between parentheses following $A$ in the equation indicate the state of the polymer films; e.g. (samp) is the polymer sample at post-exposure-baking at $140^{\circ} \mathrm{C}$ for $30 \mathrm{~min}$; (init) is non-baked film; (fin) is completely imidized film (Post-exposure-baked at $330^{\circ} \mathrm{C}$ for $30 \mathrm{~min}$ ).

\section{2-8. Photosensitivity}

PAA-2 polymer films $(17.0 \mu \mathrm{m})$ were prepared by PAA-2 $(5.0 \mathrm{~g})$, PBG $(100 \mathrm{mg})$ and DETX (30 mg), followed by casting on copper films and then prebaked at $95{ }^{\circ} \mathrm{C}$ for $12 \mathrm{~min}$. These films were exposed at $500 \mathrm{~mJ} / \mathrm{cm}^{2}$, post-exposure-baked at $110{ }^{\circ} \mathrm{C}$ for $30 \mathrm{~min}$. The development of the exposed films was performed with $1 \mathrm{wt} \%$ $\mathrm{Na}_{2} \mathrm{CO}_{3}$ aq. at $30^{\circ} \mathrm{C}$. The films were rinsed by distilled water. The normalized film thickness was calculated.

\section{2-9. Film property experiment}

PAA-2 polymer films $(17.0 \mu \mathrm{m})$ were prepared with the same method of 2-7. The films were exposed at $500 \mathrm{~mJ} / \mathrm{cm}^{2}$, post-exposure baked at $120^{\circ} \mathrm{C}$ for $60 \mathrm{~min}$ and at $180{ }^{\circ} \mathrm{C}$ for $60 \mathrm{~min}$. Film property experiment was carried out by bending test.

2-10. Thermal stability of PBGs in the presense of carboxylic acid

To a PBG $(0.025 \mathrm{mmol})$ solution in DMSO- $_{6}(0.7 \mathrm{ml})$ was added terephthalic acid (TPA) $(0.05 \mathrm{mmol})$. This solutions were set in a NMR tubes. The NMR tubes were heated between $60^{\circ} \mathrm{C}$ and $180^{\circ} \mathrm{C}$ for $20 \mathrm{~min}$. The NMR spectra were measured at every $20^{\circ} \mathrm{C}$.

\section{Results}

PBGs having acyloxyimino (AOI) group are transformed into imine or amine as shown Scheme 7. When PBG1 (1PhBA) that generates benzylamine was applied for PSPI, the resulting PI film became brittle. From GPC data, decrease of $\mathrm{Mw}$ was confirmed after curing at $180^{\circ} \mathrm{C}$. Mw of PI film

without/with $1 \mathrm{PhBA}$ was 71,000 and 21,000 , respectively.

When various base species were added to PAA, PI films prepared with imidazole, amine, pyridine showed the same mechanical properties with the blank film. However the PI film prepared with piperidine became brittle.

It was assumed that the $\mathrm{NH}$ group influenced the negative effect on the mechanical properties of PI film. It was assumed that the imine group was generated from cyclic AOI group. Then some cyclic AOI groups (PBG2 7) were designed and applied as a catalyst of PSPI.

Table 1 shows evaluation of PBGs. UV-vis spectra of PBGs were measured. $\lambda$ max of TX-8 which has a thioxanthone group was $380 \mathrm{~nm}$, however the others showed below $300 \mathrm{~nm}$.

C8 showed efficient photolysis in PMAN film. However TX-8 showed slow photolysis, and $\mathrm{C} 7 \mathrm{M}, \mathrm{C} 8 \mathrm{M}$ showed hardly photolysis. It is suggested that cyclic AOI compounds having a $\mathrm{Ph}$ group at E-position (the trans position against oxime $\mathrm{N}-\mathrm{O}$ bond) of $\mathrm{C}=\mathrm{N}$ are decomposed efficiently and group (e.g. thioxanthone group) at E-position are not decomposed efficiently. It is assumed that TX-8 is not transformed to a structure which is able to decompose at excited state because of fixed group.

The thermal stability of PBGs was evaluated by $5 \%$ weight loss temperature. $5 \%$ weight loss temperature of $\mathrm{C} 8 \mathrm{M}$ and $\mathrm{C} 7 \mathrm{M}$ were $184^{\circ} \mathrm{C}$ and $169^{\circ} \mathrm{C}$, respectively. DTA analysis of C8M and $\mathrm{C} 7 \mathrm{M}$ did not give the exothermic peak. So, it is assumed that $\mathrm{C} 8 \mathrm{M}$ and $\mathrm{C} 7 \mathrm{M}$ are volatiled without decomposition.

On the other hand, 5\% weight loss temperatures of other samples were followed in the order of $\mathrm{TX}-8>\mathrm{C} 8>\mathrm{C} 7 \mathrm{MPh}>\mathrm{C} 8 \mathrm{MPh}$. It was suggested that cyclic AOI compounds with small substituent or fixed group are more stable than those with steric hindrance substituents.

Catalytic ability of PBGs was evaluated by imidization of PAA-1 film. Diethythioxanthone 


\begin{tabular}{|c|c|c|c|c|c|c|c|c|c|}
\hline & $\begin{array}{l}\text { UV spectra } \\
\lambda \max (n \mathrm{n})\end{array}$ & $\begin{array}{l}\text { Photolysis } \\
(\%)(a)\end{array}$ & $\begin{array}{l}\text { DTA analysis }\left({ }^{\circ} \mathrm{C}\right) \\
\text { (b) }\end{array}$ & $\begin{array}{l}5 \% \text { weight loss } \\
\text { Temp. }\left({ }^{\circ} \mathrm{C}\right)(\mathrm{c})\end{array}$ & $\begin{array}{l}\text { Degree of } \\
\text { imidiztion } \\
(2000 \mathrm{~mJ} / \mathrm{cm} 2) \\
(\%)(d)\end{array}$ & $\begin{array}{l}\text { Degree of } \\
\text { imidiztion } \\
(0 \mathrm{~mJ} / \mathrm{cm} 2) \\
(\%)(\mathrm{e})\end{array}$ & $\begin{array}{l}\text { Imidization } \\
\text { difference(\%) } \\
\text { (f) }\end{array}$ & $\begin{array}{l}\text { Normalized } \\
\text { Film } \\
\text { thickness } \\
(\%)(\mathrm{g})\end{array}$ & $\begin{array}{l}\text { Film } \\
\text { Property } \\
\text { (i) }\end{array}$ \\
\hline $\mathrm{C} 8$ & 246 & 89 & 215 & 212 & 63 & 42 & 21 & 93 & $x$ \\
\hline C7M & 235 & 11 & No peak top & 165 & n.d. & n.d. & n.d. & n.d. & n.d. \\
\hline C8M & 234 & 7 & No peak top & 144 & n.d. & n.d. & n.d. & n.d. & n.d. \\
\hline C7MPh & 250 & 83 & 189 & 181 & 38 & 32 & 4 & 78 & 0 \\
\hline C8MPh & 256 & 85 & 220 & 210 & 48 & 35 & 13 & 93 & $\Delta$ \\
\hline TX-8 & $262,321,385$ & 38 & 286 & 258 & 49 & 47 & 2 & $-(h)$ & 0 \\
\hline
\end{tabular}

(a) Photolysis rate of PBGs exposed at $2000 \mathrm{~mJ} / \mathrm{cm}^{2}$ in PMAN film.

(b) Exothermic peak top of PBGs determined by TG analysis.

(c) 5\% weight loss temperature of PBSs determined by TG analysis.

(d) Degree of imidization of PAA films exposed at $2000 \mathrm{~mJ} / \mathrm{cm}^{2}$ and post-exposure-baked at $140^{\circ} \mathrm{C}$ for 30 min. (Degree of imidization of PBG-free PAA was 28\%)

(e) Degree of imidization of PAA films exposed at $0 \mathrm{~mJ} / \mathrm{cm}^{2}$ and post-exposure-baked at $140^{\circ} \mathrm{C}$ for $30 \mathrm{~min}$.

(f) Imidization degree difference of PBGs between irradiated area and no-irradiated are.

(g) No Patterning.

(h) Film property experiment (x; self-support impossible, $\Delta$; folding back impossible at bending test,, $\bigcirc$; folding back possible at bending test).

(i) Not determined.

Table 1. Evaluation of PBG7:TX-8

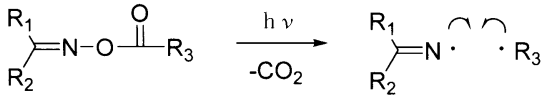

$$
\begin{aligned}
& \longrightarrow \underset{\mathrm{R}_{2}}{\rightleftharpoons}=\mathrm{N}-\mathrm{R}_{3} \stackrel{\mathrm{H}_{2} \mathrm{O}}{\longrightarrow} \underset{\mathrm{R}_{2}}{=}=\mathrm{O} \quad \mathrm{H}_{2} \mathrm{~N}-\mathrm{R}_{3}
\end{aligned}
$$

Scheme 7 Photolysis of acyloxyimino group

(DETX) was adopted as a photo-sensitizer. The degree of imidization of photo irradiated area $\left(2000 \mathrm{~mJ} / \mathrm{cm}^{2}, \mathrm{PEB} ; 140^{\circ} \mathrm{C} / 30 \mathrm{~min}\right)$ was compared with that of no-irradiated area $\left(0 \mathrm{~mJ} / \mathrm{cm}^{2}\right.$, PEB $\left.; 140^{\circ} \mathrm{C} / 30 \mathrm{~min}\right)$. The degree of imidizations of photo irradiated area showed the following order, $\mathrm{C} 8>\mathrm{TX}-8>\mathrm{C} 8 \mathrm{MPh}>\mathrm{C} 7 \mathrm{MPh}$. However, that of no-irradiated area showed the following order, TX- $8>\mathrm{C} 8>\mathrm{C} 8 \mathrm{MPh}>\mathrm{C} 7 \mathrm{MPh}$. Hence the differences of between irradiated area and no-irradiated area showed the following order, $\mathrm{C} 8>\mathrm{C} 8 \mathrm{MPh}>\mathrm{C} 7 \mathrm{MPh}>\mathrm{TX}-8$. Although TX-8 showed the highest thermal stability in TG/DTA analysis, the dark-reaction proceeded in case of TX-8. It was assumed that TX-8 became unstable state by $\mathrm{COOH}$ of PAA side-chain, so the thermal decomposition occurred and caused dark-reaction. In case of $\mathrm{C} 8$, the degree of imidization in irradiated area was high and that of no-irradiated area was also high. On the other hand, in case of $\mathrm{C} 8 \mathrm{M}-\mathrm{Ph}$, the degree of imidization in irradiated area was smaller than in case of $\mathrm{C} 8$, however dark-reaction was also smaller. As a result, the difference between irradiated area and no-irradiated area was larger than any other samples. So it is suggested that $\mathrm{C} 8 \mathrm{M}-\mathrm{Ph}$ is suitable as the catalyst of PSPI.

The phtosensitivity of PBGs was evaluated with the normalized film thickness. The normalized film thicknesses showed the following order, $\mathrm{C} 8 \mathrm{MPh}>\mathrm{C} 8>\mathrm{C} 7 \mathrm{MPh}$. The film residue of TX-8 was not observed after development.

The film property was evaluated by bending test. The film properties of $\mathrm{PBG}$ showed the following order, TX-8 $\fallingdotseq$ $\mathrm{C} 7 \mathrm{MPh}>\mathrm{C} 8 \mathrm{MPh}>\mathrm{C} 8$. It is supposed that the decrease of film property results from PAA degradation by the thermolysis product of PBGs. However, these results were not 
associated with thermal stability results. Hence, we evaluated the thermal decomposition of PBGs in the presense of a carboxylic acid.

The thermal decomposition of PBGs was evaluated in the presence of TPA. Thermal stabilities of PBGs in the presence of TPA showed the following order, $\mathrm{C} 8 \mathrm{MPh}>\mathrm{C} 7 \mathrm{M}>\mathrm{C} 8>\mathrm{C} 7 \mathrm{MPh}>\mathrm{C} 8 \mathrm{M}>\mathrm{TX}-8$. The thermal stability of TX-8 decreased especially in case of in the presence of TPA. However, these results were also not associated with the film property results obtained by bending test.

We suppose that the film properties are influenced by the molecular structures of PBG thermolysis products and/or PAA's degradability. Although TX-8 was not stable in the presence of a carboxyl acid, the film property of TX-8 was comparatively high. It is assumed that the thermolysis product of TX-8 is not induced the PAA's degradation.

We suppose that the thermal stability of PBGs in the presence of carboxyl acid is also important. We consider that these stabilities were associated with properties of substituents, i.e. electron-withdrawing and electrondonationg group. For example, nitro group (electron withdrawing group) or methoxy group (electron-donating group) will be able to control the stability.

\section{Conclution}

The large absorption of PBGs corresponding i-line was accomplished by the introduction of a thioxanthone group. It is suggested that cyclic AOI compounds having a $\mathrm{Ph}$ group at E-position of $\mathrm{C}=\mathrm{N}$ (the trans position against oxime $\mathrm{N}-\mathrm{O}$ bond) decompose efficiently by irradiation. And cyclic AOI compounds having fixed group (e.g. thioxanthone group) at E-position do not decompose efficiently by irradiation. On the other hand, it is suggested that cyclic AOI compounds with small substituent or fixed group are more stable than those with bulky substituents. Hence, the molecular designe for a balance between PBG's photolysis and PBG's thermal stability is important. Therefore we consider that thermal stability of PBGs in the presence of carboxyl acid is important for applying PSPIs.

\section{Acknowledgement}

The authors are greatly indebted to Prof. M. Shirai of Department of Applied Chemistry, Osaka Prefecture University.

\section{References}

1. M.Tsunooka, S.Imoto, K.Nakayama, H.Kuwabara, and M.Tanaka, J. Polym. Sci., Polym. Chem. Ed., 24, 317 (1986).

2. Ken-ichi Ito, Masamichi Nishimura, Minoru Sashio,and Masahiro Tsunooka

J. Polym. Sci.:Part A:Polym. Chem. 32, 2177-2185 (1994).

3. JPA2007-223968 